\title{
A POTENCIALIDADE DA BIOMASSA DE Spirulina sp. LEB 18 COMO MATÉRIA PRIMA NA CONCEPÇÃO DE UMA BIORREFINARIA
}

\author{
J. CORÁ ${ }^{1}$, J. B. MOREIRA ${ }^{1}$, A. L. M. TERRA ${ }^{1}$, J. A. V. $\operatorname{COSTA}^{1}$, M. G. de MORAIS ${ }^{1}$ \\ ${ }^{1}$ Universidade Federal do Rio Grande, Escola de Química e Alimentos \\ E-mail para contato: michele.morais@pq.cnpq.br
}

\begin{abstract}
RESUMO - As microalgas são micro-organismos fotossintéticos procarióticos e eucarióticos, que apresentam biomassa rica em polissacarídeos, proteínas, lipídios e/ou hidrocarbonetos. O objetivo deste trabalho foi caracterizar a biomassa de Spirulina sp. LEB 18 cultivada com $\mathrm{CO}_{2}$ em modo semicontínuo, verificando sua potencialidade na concepção de uma biorrefinaria. A microalga foi mantida em meio Zarrouk e Zarrouk modificado com $10 \%$ (v/v) de $\mathrm{CO}_{2}$. As taxas de renovação estudadas foram 20 e $40 \%$ $(\mathrm{v} / \mathrm{v})$. As maiores concentrações proteicas foram encontradas nos ensaios com $\mathrm{CO}_{2}$, sendo 60,1 e $59,7 \%$ (p/p) com as taxas de renovação de 20 e $40 \%$ (v/v), respectivamente. O máximo teor lipídico, $9,8 \%(\mathrm{p} / \mathrm{p})$, foi obtido do ensaio com $\mathrm{CO}_{2} \mathrm{e}$ renovação de $20 \%(\mathrm{v} / \mathrm{v})$. Os teores máximos de cinzas e carboidratos foram obtidos dos cultivos com meio Zarrouk e renovação de $20 \%$ (v/v). A partir da biomassa de Spirulina sp. LEB 18 é possível a obtenção de bioprodutos como biopeptídeos, ácidos graxos essenciais e bioetanol, reduzindo ainda as emissões de $\mathrm{CO}_{2}$ para a atmosfera.
\end{abstract}

\section{INTRODUÇÃO}

$\mathrm{O}$ aumento nas emissões de $\mathrm{CO}_{2}$ pode resultar em elevação significativa da temperatura no planeta. Diante disso, governos têm debatido sobre formas de minimizar essas emissões, sem prejudicar o crescimento econômico. Os acordos se baseiam em redução das emissões, aquisição de créditos de carbono, implementação de projetos baseados em tecnologias limpas em outros países. Países desenvolvidos podem investir em projetos em países em desenvolvimento, com a promoção de sequestro de carbono, contabilizando redução em suas emissões (Barreto et al., 2009). A redução do uso de combustíveis fósseis, bem como promover a captura e sequestro de $\mathrm{CO}_{2}$ são alternativas para reduzir as emissões deste gás (Ho et al., 2010) e micro-organismos como as microalgas são potenciais atuantes nesse processo.

As microalgas são consideradas como um sistema biológico eficiente para a captação de energia solar e produção de componentes orgânicos. A produção de microalgas pode ser realizada durante todo o ano, necessitando de pouca água quando comparada a plantas terrestres. A composição bioquímica das microalgas pode ser manipulada, através da alteração das condições de cultivo e estresses ambientais ( $\mathrm{Hu}$ et al., 2008), sendo induzidas a produzirem altas concentrações de biocompostos de importância comercial e o rendimento em lipídios pode ser significativamente melhorado. As microalgas podem produzir, além de lipídios, proteínas, carboidratos que podem ser utilizados como alimento ou fermentados para produzir etanol, metano, dentre outros bioprodutos com maior valor agregado (Brennan e Owende, 2010). Entre as abordagens para redução das emissões de $\mathrm{CO}_{2}$, a biofixação desse gás por microalgas é 
considerada uma das soluções mais eficazes (Morais e Costa, 2007).

Cultivos semicontínuos de microalgas tornam-se alternativas para produção em maior escala. Esse modo de cultivo apresenta vantagens operacionais, como dispensar a constante troca de inóculo, além de manter o micro-organismo em elevadas velocidades de crescimento. No cultivo semicontínuo o mesmo inóculo pode ser utilizado por longo período, além de manter o controle de parâmetros nutricionais e cinéticos (Reichert et al., 2006).

A biorrefinaria é considerada como processamento sustentável, que integra os processos de conversão de biomassa para produzir biocombustíveis, produtos de valor agregado e energia. A combinação dos benefícios pelo uso das microalgas na produção de biocombustíveis e biocompostos, a biofixação de $\mathrm{CO}_{2}$, dentre outras vantagens, apontam o grande potencial de aplicação das microalgas em biorrefinarias (Borges, 2010). Para uma biorrefinaria baseada em microalgas ser autossustentável e ambientalmente correta é necessário o uso de fontes alternativas de carbono originadas de efluentes industriais $\left(\mathrm{CO}_{2}\right)$ para redução dos custos de produção, bem como a obtenção de no mínimo três bioprodutos. Além disso, a condução de cultivo deve proporcionar alta produtividade de biomassa, o que pode ser obtida em processo semicontínuo.

Diante do exposto, o objetivo deste trabalho foi caracterizar a biomassa de Spirulina sp. LEB 18 cultivada com $\mathrm{CO}_{2}$ em modo semicontínuo, verificando sua potencialidade na concepção de uma biorrefinaria.

\section{MATERIAL E MÉTODOS}

\subsection{Micro-organismo e Condições de Cultivo}

A microalga utilizada neste estudo foi Spirulina sp. LEB 18 (Morais et al., 2008), mantida em meio Zarrouk (Zarrouk, 1966) e Zarrouk modificado substituindo-se a fonte original de carbono (16 g. $\mathrm{L}^{-1}$ de $\left.\mathrm{NaHCO} 3\right)$ por $10 \%(\mathrm{v} / \mathrm{v})$ de $\mathrm{CO}_{2}$. Os cultivos foram realizados em duplicata, sob condições controladas em câmara termostatizada a $30^{\circ} \mathrm{C}, 41,6 \mathrm{umol} / \mathrm{m}^{2} . \mathrm{s}$ e fotoperíodo $12 \mathrm{~h}$ claro/escuro, com iluminação provida por lâmpadas fluorescentes de $40 \mathrm{~W}$.

A concentração inicial de biomassa no cultivo de Spirulina sp. LEB 18 foi de 0,2 g.L L $^{-1}$. A microalga foi cultivada em fotobiorreatores tubulares verticais de $2 \mathrm{~L}$, com volume útil de $1,5 \mathrm{~L}$. A aeração foi realizada por aspersão de pedra porosa, através de ar comprimido misturado ao $\mathrm{CO}_{2}$ disposto em cilindro industrial (White Martins). A vazão de entrada da mistura nos cultivos foi 0,3 vvm, controlada através de válvula solenóide. A injeção de $10 \%$ (v/v) de $\mathrm{CO}_{2}$ foi realizada diretamente nos fotobiorreatores, a cada $2 \mathrm{~h}$, durante $10 \mathrm{~min}$, no período claro.

Os cultivos foram conduzidos em modo semicontínuo, em que, a concentração celular de corte foi definida como aquela encontrada no final da fase exponencial de crescimento. As taxas de renovação estudadas foram 20 e $40 \%$ (v/v).

\subsection{Concentração de Biomassa Microalgal e Biomassa Produzida}

Diariamente foram coletadas amostras para determinação da concentração de biomassa, calculada através da densidade ótica a $670 \mathrm{~nm}$ (Costa et al., 2002) em espectrofotômetro 
(Q7980RM, Quimis, Brasil) com curva de calibração relacionando densidade ótica e peso seco de biomassa da microalga.

A biomassa produzida $\left(\mathrm{B}_{\mathrm{P}}\right)$ foi calculada a partir da Equação 1, em que $\mathrm{V}_{\mathrm{c}}$ é o volume retirado de cada corte $(\mathrm{mL}), \mathrm{BC}_{1}$ é a concentração de biomassa $\left(\mathrm{g} \cdot \mathrm{L}^{-1}\right)$ obtida a partir do $1^{\circ}$ corte, $\mathrm{BC}_{2}$, do $2^{\circ}$ corte. $\mathrm{A} \mathrm{BC}_{\mathrm{n}}$ é a concentração de biomassa obtida no último dia de cultivo ( $\mathrm{g}$. $\mathrm{L}^{-1}$ ) e $\mathrm{V}_{\mathrm{f}}$ é o volume útil do fotobiorreator $(\mathrm{mL})$.

$$
B_{P}=\Sigma\left[V_{c} *\left(B C_{1}+B C_{2}+\ldots\right)+\left(B C_{n} * V_{f}\right)\right]
$$

\subsection{Caracterização da Biomassa Microalgal}

A partir de cada corte realizado no cultivo semicontínuo, a biomassa microalgal foi recuperada por centrifugação a $16920 \mathrm{~g}, 20^{\circ} \mathrm{C}$ por 20 min para separá-la do meio de cultivo. Posteriormente, foi realizada lavagem com água destilada, para eliminação de resíduos de sais do meio e foi realizada novamente a centrifugação. Em seguida, a biomassa microalgal foi armazenada sob refrigeração a $-20^{\circ} \mathrm{C}$. Ao final do cultivo semicontínuo, juntou-se as biomassas obtidas em cada corte, as amostras foram congeladas a $-80^{\circ} \mathrm{C}$, liofilizadas e então, realizou-se a caracterização.

As biomassas obtidas dos cultivos semicontínuos foram caracterizada quanto ao teor de carboidratos pelo método fenol-sulfúrico (Dubois et al., 1956), proteínas pelo método colorimétrico de Lowry (Lowry et al., 1951), e lipídios por Folch e Less (1957). O teor de umidade e cinzas foi determinado segundo a metodologia da AOAC (2000). As análises foram realizadas em triplicata e os resultados, apresentados em base seca.

\subsection{Análise Estatística}

Os resultados de composição química das biomassas foram avaliados por Análise de Variância (ANOVA), com nível de confiança de 95\% (p $\leq 0,05)$, utilizando teste de Tukey.

\section{RESULTADOS E DISCUSSÃO}

Quando a microalga Spirulina sp. LEB 18 foi cultivada com $\mathrm{CO}_{2}$ como fonte de carbono, foi apresentado os maiores números de ciclos de crescimento da microalga, sendo 18 e 9 ciclos, nos cultivos com taxas de renovação de 20 e 40\%, respectivamente. O final da fase exponencial de crescimento foi 1,6 g. $\mathrm{L}^{-1}$, sendo determinada esta a concentração celular de corte (Figuras 1a e $1 b)$. 
(a)

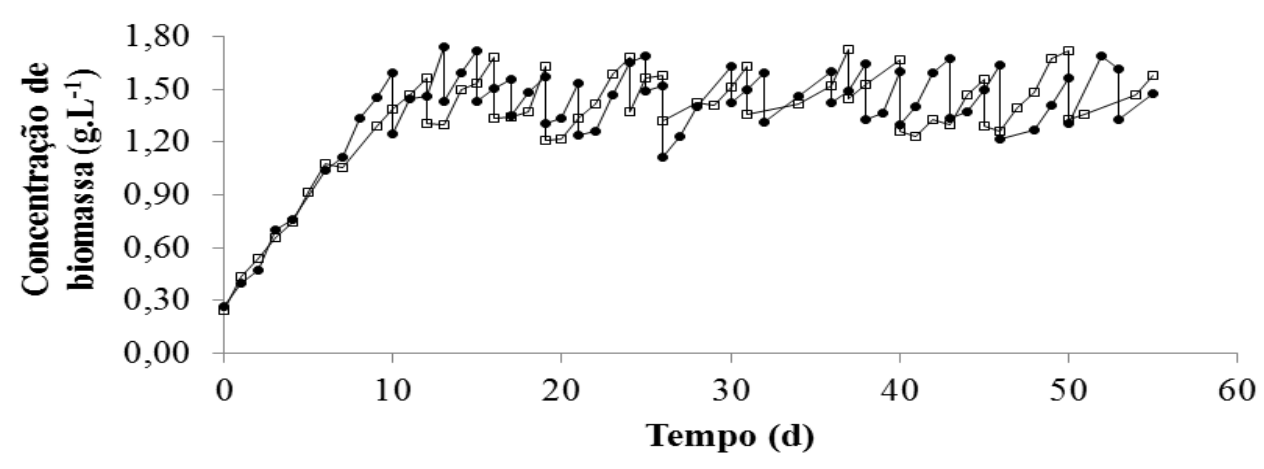

(b)

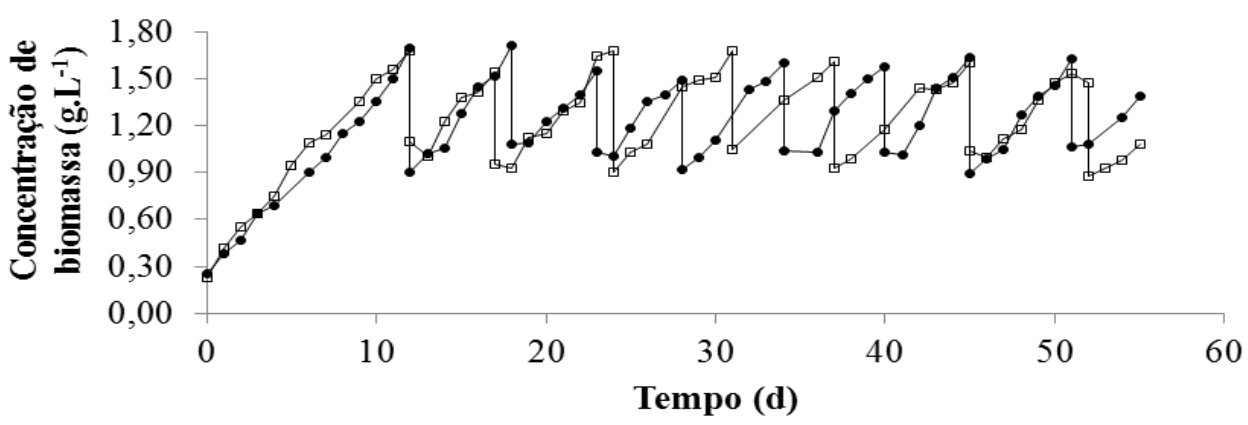

Figura 1 - Curvas de crescimento da microalga Spirulina sp. LEB 18 com taxa de renovação de $20 \%$ (a) e $40 \%$ (b): meio Zarrouk ( $\square$ ); substituição das fontes de carbono do meio Zarrouk, por

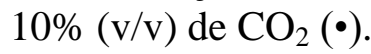

Nota-se que nos cultivos da microalga Spirulina sp. LEB 18 não houve fase de adaptação. A fase de adaptação ou fase lag ocorre pela necessidade das células se adaptarem ao novo meio, até que possam dar início ao seu desenvolvimento (Brock e Brock, 1978). Essa fase não foi observada neste trabalho (Figuras 1a e 1b) porque as diferenças entre as condições de cultivo e a manutenção do inóculo antes do experimento foram discretas, onde a temperatura, iluminância e aeração foram mantidos iguais.

A influência da concentração de $\mathrm{CO}_{2}$ nos cultivos foi observada, uma vez que o incremento de $\mathrm{CO}_{2}$ nos cultivos proporcionou aumento da quantidade de biomassa produzida $\left(\mathrm{B}_{\mathrm{P}}\right)$ de $39,7 \%$ (p/p), com a taxa de renovação de $20 \%$ (v/v). Ao final do cultivo semicontínuo da microalga, com a renovação de $20 \%$ (v/v) foi produzido $7,5 \mathrm{~g}$ de biomassa quando mantida em meio Zarrouk e 10,5 g, em meio Zarrouk modificado com $10 \%$ (v/v) de $\mathrm{CO}_{2}$.

A cada ciclo de Calvin completo são produzidos carboidratos, mas ácidos graxos, aminoácidos e ácidos orgânicos também podem ser sintetizados na fixação fotossintética de $\mathrm{CO}_{2}$ (Masojídek et al., 2004). Quando cultivada com meio Zarrouk, a microalga Spirulina sp. LEB 18 apresentou biomassa com teor de 19,1 e 18,8 \% (p/p) de carboidratos, com taxa de renovação de 20 e $40 \%$ (v/v), respectivamente (Tabela 1$)$. 
Tabela 1 - Composição química da biomassa de Spirulina sp. LEB 18

\begin{tabular}{|c|c|c|c|c|}
\hline $\begin{array}{c}\mathrm{TR} \\
(\%, \mathrm{v} / \mathrm{v})\end{array}$ & $\begin{array}{c}\text { Carboidratos* } \\
(\%, \mathrm{p} / \mathrm{p})\end{array}$ & $\begin{array}{c}\text { Proteínas* } \\
(\%, \mathrm{p} / \mathrm{p})\end{array}$ & $\begin{array}{c}\text { Lipídios* } \\
(\%, \mathrm{p} / \mathrm{p})\end{array}$ & $\begin{array}{l}\text { Cinzas* } \\
(\%, \mathrm{p} / \mathrm{p})\end{array}$ \\
\hline \multicolumn{5}{|c|}{ Meio Zarrouk } \\
\hline 20 & $19,1 \pm 0,97^{\mathrm{a}}$ & $42,9 \pm 4,50^{b}$ & $9,2 \pm 0,65^{\mathrm{a}}$ & $28,1 \pm 1,90^{\mathrm{a}}$ \\
\hline 40 & $18,8 \pm 1,00^{\mathrm{a}}$ & $47,8 \pm 2,25^{\mathrm{b}}$ & $9,3 \pm 1,39^{\mathrm{a}}$ & $22,7 \pm 0,97^{b}$ \\
\hline \multicolumn{5}{|c|}{ Meio Zarrouk modificado $\left(10 \%(\mathrm{v} / \mathrm{v}) \mathrm{CO}_{2}\right)$} \\
\hline 20 & $13,7 \pm 0,45^{\mathrm{b}}$ & $60,1 \pm 1,18^{\mathrm{a}}$ & $9,8 \pm 0,61^{\mathrm{a}}$ & $14,4 \pm 0,94^{\mathrm{c}}$ \\
\hline 40 & $14,4 \pm 0,35^{\mathrm{b}}$ & $59,7 \pm 1,66^{\mathrm{a}}$ & $8,8 \pm 1,01^{\mathrm{a}}$ & $13,8 \pm 0,92^{\mathrm{c}}$ \\
\hline
\end{tabular}

*: Valores são média \pm desvio padrão; Letras iguais na mesma coluna não diferem estatisticamente $(\mathrm{p}>0,05)$ pelo teste de Tukey.

As maiores concentrações proteicas obtidas para a microalga Spirulina sp. LEB 18 foram nos ensaios com $\mathrm{CO}_{2}$ como fonte de carbono. Segundo Lourenço et al. (2004), se o suprimento de nitrogênio é abundante em cultivos, verifica-se tendência de aumento nas concentrações de proteínas e de clorofila nas células. Contrariamente, quando as concentrações de nitrogênio disponíveis para as microalgas são baixas, verifica-se redução da taxa de divisão celular, proteínas e clorofila. De acordo com a literatura, o teor de proteínas é maior durante a fase exponencial de crescimento (Valenzuela-Espinoza et al., 2002). Isso também pode justificar os teores de proteínas relativamente elevados obtidos nas biomassas da microalga Spirulina sp. LEB 18.

Quando analisada a composição química da microalga Spirulina sp. LEB 18 nota-se que houve relação inversa no teor de proteínas e carboidratos. Os maiores teores de proteínas e menor de carboidratos foram os obtidos quando a microalga foi cultivada com $10 \%$ (v/v) de $\mathrm{CO}_{2}$. Outros estudos apresentaram respostas semelhantes. Derner (2006) constatou que a utilização de $\mathrm{CO}_{2}$ causou aumento no conteúdo de proteínas, especialmente em culturas de T. fluviatilis.

A biomassa microalgal apresentou máximo teor de lipídios no ensaio com $10 \%(\mathrm{v} / \mathrm{v})$ de $\mathrm{CO}_{2} \mathrm{e}$ renovação de $20 \%$ (v/v). Tsuzuki et al. (1990), relatam que a adição de $\mathrm{CO}_{2}$ às culturas microalgais influencia na quantidade de lipídios e no grau de insaturação dos ácidos graxos, sendo portanto, um nutriente essencial nos cultivos. O acúmulo de lipídios ocorre quando o acetil-CoA é convertido em malonil-CoA seguido por ácidos graxos após ciclos contínuos, catalisada pela acetil-CoA carboxilase (ACCase). O acúmulo de lipídios ocorre no cloroplasto e ACCase exerce intensa regulamentação da síntese de ácidos graxos em microalgas (Lv et al., 2010). Nos cloroplastos, dependendo do estágio de desenvolvimento da célula, a atividade da piruvato desidrogenase é frequentemente baixa. Por outro lado, acetil-CoA sintetase nos cloroplastos possui alta afinidade pelo acetato e consome ATP para converter a acetil-CoA (Heldt, 2005). Assim, a adição de $\mathrm{CO}_{2}$ nos cultivos de Spirulina sp. LEB 18 proporcionou rapidamente a síntese de ATP para converter a acetil-CoA e iniciar a biossíntese de lipídios.

Relacionado ao teor de cinzas foi observado que os ensaios com $\mathrm{NaHCO}_{3}$ como fonte de carbono apresentaram os máximos valores de cinzas, sendo justificada pela elevada concentração desse nutriente no meio Zarrouk (16,8 g. $\left.\mathrm{L}^{-1}\right)$. Nos ensaios com $\mathrm{CO}_{2}$ sendo a fonte de carbono, os teores de cinzas foram menores, uma vez que o $\mathrm{NaHCO}_{3}$ do meio Zarrouk foi substituído por $10 \%$ $(\mathrm{v} / \mathrm{v})$ de $\mathrm{CO}_{2}$. 
Assim, em uma biorrefinaria microalgal nas condições realizadas neste estudo, as proteínas poderiam ser utilizadas para alimentação humana ou ainda para obtenção de peptídeos bioativos que poderiam ser nanoencapsulados e adicionados à produtos alimentícios. Os carboidratos poderiam ser utilizados para produção de bioetanol, os lipídios para biodiesel, biossurfactantes ou ácidos graxos essenciais e as cinzas poderiam retornar aos cultivos como fonte de minerais.

\section{CONCLUSÃO}

Quando cultivada com $10 \%$ (v/v) de $\mathrm{CO}_{2}$ e taxa de renovação de $20 \%$ (v/v), a microalga Spirulina sp. LEB 18 apresentou biomassa rica em proteínas, sendo 60,1\% (p/p), 14,4\% (p/p) de carboidratos e máximo teor lipídico de $9,8 \%$ (p/p). A partir da biomassa de Spirulina sp. LEB 18 é possível a obtenção de bioprodutos como biopeptídeos, bioetanol, ácidos graxos essenciais, biogás, reduzindo ainda as emissões de $\mathrm{CO}_{2}$ para a atmosfera.

Assim, para concepção de uma biorrefinaria microalgal, o uso da biomassa de Spirulina sp. LEB 18 como matéria prima pode ser considerada ambientalmente correta e economicamente sustentável, quando cultivada em modo semicontínuo com $\mathrm{CO}_{2}$ como fonte de carbono e renovação de $20 \%(\mathrm{v} / \mathrm{v})$.

\section{AGRADECIMENTOS}

Os autores agradecem a CAPES e a CGTEE - Companhia de Geração Térmica de Energia Elétrica - pelo apoio financeiro.

\section{REFERENCIAS}

AOAC- Official Methods of Analysis of the Association of Official Analytical Chenusts, 17 th HORWITZ, W.; ed. Maryland: Association of Official Analytical Chemists, 2000.

BARRETO, L. V.; FREITAS, A. C. S.; PAIVA,L. C. Sequestro de Carbono. Centro Cientifico Conhecer. Goiânia, Enciclopédia Biosfera, 2009.

BORGES, F.C. Proposta de um modelo conceitual de biorrefinaria com entrutura descentralizada. Dissertação de Mestrado - Universidade Federal do Rio Grande do Sul, Porto Alegre, 2010.

BRENNAN, L; OWENDE, P. Biofuels from microalgae - a review of technologies for production, processing, and extractions of biofuels and coproducts. Renew Sust Energ Rev., v. 14, p. 557$577,2010$.

BROCK, T.D.; BROCK, K.M. Basic microbiology with applications. 2.ed. Englewood Cliffs: Prentice Hall, 1978. 608p.

COSTA, J. A. V., COLlA, L. M., DUARTE FILHO, P., KABKE, K., WEBER, A. Modelling of Spirulina platensis growth in fresh water using response surface methodology. World $J$ of Microb Biot., v.18, p. 603-607, 2002.

DERNER, R.B. Efeito de fontes de carbono no crescimento e na composição bioquímica das microalgas Chaetoceros muelleri e Thalassiosira fluviatilis, com ênfase no teor de ácidos graxos poli-insaturados. Tese de Doutorado - Universidade Federal de Santa Catarina, Florianópolis, 2006. 
DUBOIS, M.; GILLES, K. A.; HAMILTON, J. K.; REBERS, P. A.; SMITH, F. Colorimetric method for determination of sugars and related substances. Anal Chem., v. 28, p. 350-356, 1956.

FOLCH, J.; LEES, M. A simple method for isolation and purification of total lipids from animal tissues. J Biol Chem., v. 226, p. 497-509, 1957.

HELDT. H. W. Plant biochemistry. 3th. ed. San Diego: Elsevier Academic Press, 2005. 629p.

HO, S.H.; CHEN, W. M.; CHANG, J. S.; Scenedesmus obliquus CNW-N as a potential candidate for $\mathrm{CO}_{2}$ mitigation and biodiesel production. Bioresource Technol., v. 101, p. 8725-8730, 2010 .

HU, Q.; SOMMERFELD, M.; JARVIS, E.; GHIRARDI， M.; POSEWITZ, M.; SEIBERT， M.; DARZINS, A. Microalgal Triacylglycerols as feedstocks for biofuel production and advances. Plant J., v. 54, p. 621-639, 2008.

LOURENÇO, S. O.; BARBARINO, E.; LAVÍN, P. L.; MARQUEZ, U. M. L.; AIDAR, E. Distribution of intracelular nitrogen in marine microalgae. Calculation of new nitrogen-toprotein conversion factors. Eur J Phycol., v.41, p. 17-32, 2004.

LOWRY, O. H. ROSEBROUGH, N. J.; FARR, A. L.; RANDALL, R. L. Protein measurement with the folin phenol reagent. J Biol Chem., v.193, p. 265-275, 1951.

LV, J. M.; CHENG, L.H.; XU, X. H.; ZHANG, L.; CHEN, H. L. Enhanced lipid production of Chlorella vulgaris by adjustment of cultivation conditions. Bioresource Technol., v. 101, p. 6797-6804, 2010.

MASOJÍDEK, J.; KOBLÍZEK, M.; TORZILLO, G. Photosynthesus in Microalgae: In RICHMOND, A. Handbook of Microalgal Culture: Biotechnology and Applied Phycology. Blackwell Science Ltd a Blackwell Publishing company, 2004.

MORAIS, M. G.; REICHERT, C. C.; DALCANTON, F.; DURANTE, A. J.; MARINS, L. F.; COSTA, J. A. V. Isolation and characterization of a new Arthrospira strain. Z Naturforsch C., v. 63, p. 144-150, 2008.

MORAIS, M.G. de, COSTA, J. A. V. Biofixation of carbon dioxide by Spirulina sp and Scenedesmus obliquus cultivated in a three-stage serial tubular photobioreactor, J Biotechnol., v. 129 p.439-445, 2007.

REICHERT C. C.; REINEHR C. O.; COSTA J. A. V. Semicontinuous cultivation of the cyanobacterium Spirulina platensis in a closed photobioreactor. Braz J Cheml Eng., v. 23, p. 23-28, 2006.

TSUZUKI, M.; OHNUMA, E.; SATO, N.; TAKAKU, T.; KAWAGUCHI, A. Effects of $\mathrm{CO}_{2}$ Concentration during Growth on Fatty Acid Composition in Microalgae. Plant. Physiol., v. 93, p. 851-856, 1990.

VALENZUELA-ESPINOZA， E.; MILLÁN-NÚÑEZ, R.; NÚÑEZ-CEBRERO, F. Protein, carbohydrate, lipid and chlorophyll a content in Isochrysis aff. Galbana (clone T-Isso) cultured with a low cost alternative to the f/2 medium. Aquacult Eng., v.25, p.207-216, 2002.

ZARROUK, C. Contribuition a Letude Dune Cyanophycee, Influence de Divers Facteurs physiques et Chimiques sur la Croissance et photosynthese de Spirulina maxima geitler. Ph.D. Thesis University of Paris. 1966. 